\title{
Medicina e investigaciones nazis
}

\section{Nazi medicine and research}

\author{
Iván R. Zúñiga-Carrasco ${ }^{1 *}$ y Reyna Miliar-de Jesús ${ }^{2}$
}

${ }^{1}$ Departamento de Epidemiología, Unidad de Medicina Familiar 223, Instituto Mexicano del Seguro Social, Lerma de Villada; ${ }^{2}$ Unidad de Terapia Intensiva, Instituto de Seguridad Social del Estado de México y Municipios, Metepec. Estado de México, México

\section{Resumen}

Antecedentes: La historia de la medicina tiene temas que han destacado por su importancia. Algunos han ido quedado en el olvido a lo largo de los años y uno de ellos ha sido olvidado por su crueldad en contra de la dignidad del ser humano: los experimentos realizados por los médicos y científicos nazis en los campos de concentración alemanes. La «ciencia de la raza» llegó a constituir una base substancial en la formación médica durante la época nazi, numerosos delitos de lesa humanidad encontraron en ella un fundamento teórico, que los exculpaba en aras de la medicina. Objetivo: Realizar una revisión sistemática sobre la medicina y las investigaciones nazis y cómo los médicos participaron en el holocausto. Material y métodos: Búsqueda selectiva de literatura en PubMed, Medscape y Google Académico utilizando términos de búsqueda tales como experimentos nazis, medicina nazi y eugenesia. Resultados: Del material recolectado son pocos los artículos en idioma español, generalmente la mayoría está en inglés e incluso polaco. Conclusiones: Todo el personal de salud desde su formación debe conocer este tipo de temas que, aunque son tristes, no deben pasarse por alto o darse por vistos, ya que ello concienciará a los estudiantes de la importancia de estos experimentos.

Palabras clave: Investigaciones nazis. Medicina nazi. Campos de concentración. Eugenesia. Auschwitz.

\section{Abstract}

Background: The history of medicine has themes that have stood out for their importance, some have been forgotten over the years, and one of them has been forgotten for its cruelty against the dignity of the human being: the experiments carried out by Nazi doctors and scientists in German concentration camps. The "science of the race" became a substantial basis in medical training during the Nazi era, numerous crimes against humanity found in it a theoretical foundation, which exonerated them for the sake of medicine. Objective: To conduct a systematic review of Nazi medicine and research and how doctors participated in the holocaust. Methods: Selective literature search in PubMed, Medscape, and Google Scholar using search terms such as Nazi experiments, Nazi medicine, and eugenics. Results: Of the collected material there are few articles in Spanish language, generally the majority is in English and even Polish. Conclusions: All health personnel from their training should know this type of topics that, although sad, should not be overlooked or taken for granted, since this will make students aware of the importance of these experiments.

Key words: Nazi research. Nazi medicine. Concentration camps. Eugenics. Auschwitz.

Correspondencia:

*Iván R. Zúñiga-Carrasco

E-mail: ivan.zuniga@imss.gob.mx
Disponible en internet: 14-01-2021 Rev Hosp Jua Mex. 2020;87(4):214-222

www.revistahospitaljuarez.com 1405-9622/@ 2020 Sociedad Médico-Quirúrgica del Hospital Juárez de México, A.C. Publicado por Permanyer. Este es un artículo open access bajo la licencia CC BY-NC-ND (http://creativecommons.org/licenses/by-nc-nd/4.0/). 


\section{Introducción}

Podemos iniciar definiendo los experimentos con seres humanos, los cuales son intervenciones médicas bien definidas que implican tratamientos de prueba, realizados con seres humanos, con el fin de obtener resultados empíricos indispensables y difíciles de obtener de otro modo. En esta área se incluyen los tratamientos curativos de nueva creación de indiscutible relevancia, los cuales no pueden ser adoptados sin una prueba clínica de eficacia terapéutica. Por ejemplo, en la reciente pandemia de coronavirus, con la finalidad de curar a los pacientes infectados se innovaron diversas medidas terapéuticas con medicamentos retrovirales, antibióticos antipalúdicos y antiparasitarios, reportados tempranamente en publicaciones medicas de renombre, pero sin que esto nos hiciera retroceder hasta llegar a la época de las investigaciones nazis. La situación social y económica de los médicos alemanes, ya de por sí difícil debido a la crisis económica internacional, se hizo aún más aguda entre los años 19291933. Esta situación implicó dos consecuencias importantes para el gremio médico. Primero, aumentó el antisemitismo en un ámbito de nacionalismo étnico-racial, ampliamente difundido entre los médicos. La profesión médica había sido, dentro de las profesiones liberales, una de las carreras abiertas para los judíos y con el transcurso del tiempo en las grandes ciudades los médicos judíos habían alcanzado un número importante. Los nazis intensificaron sus esfuerzos de captación de médicos, basándose en la idea de que no habría ninguna profesión tan significativa como la del médico para la grandeza y el futuro de la nación. Así mismo, se calculó cuánto costaba la manutención de seres humanos con debilidad física o mental, cantidades que eran definidas como pérdidas para la nación'. El Instituto de Fráncfort, de uno de los connotados expertos de la «ciencia de la raza», Ottmar Freiherr von Verschuer, colaboró con la Sección Médicos de las Escuadras de Defensa (Schutzstaffel, SS por sus siglas en alemán) en la formación de futuros médicos. Uno de los asistentes de Verschuer, desde 1933, fue el Dr. Josef Mengele, quien bajo la protección de otro destacado experto, Mollison, alcanzó la promoción en la especialidad de antropología ${ }^{2,3}$. Sobre el fundamento ideológico de estas reflexiones estratégicas en la concepción nazi, las medidas «eugénicas» se ubican en las propuestas del Programa Nacionalsocialista (NSDAP, Nationalsozialistische Deutsche Arbeiterpartei) ${ }^{4}$. En 1939, Hitler instruyó a su médico personal, Karl Brandt, a citar un comité para preparar el programa secreto

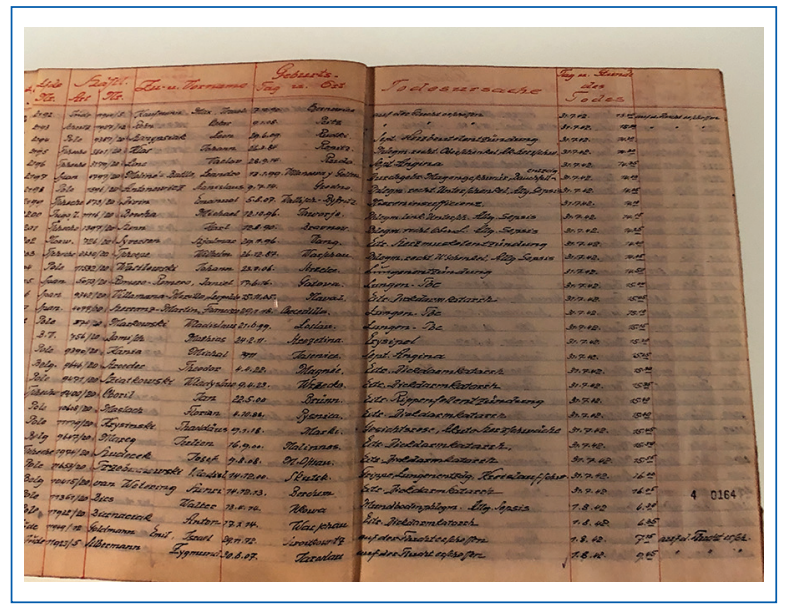

Figura 1. Falsas causas de muerte registradas por médicos de la SS.

de "asesinos de la misericordia", aplicable en niños deformados y retrasados. Así nació la T4 Aktion (el nombre viene de la villa en la calle Tiergarten 4 en Berlín), de donde derivó su nombre en clave: T45,6. El Estado deseaba impedir la aparición de aquellas enfermedades mentales que los médicos no pueden curar. Así se ahorraría grandes gastos no productivos para la totalidad del pueblo. Las instalaciones para dar muerte estaban rodeadas de especiales medidas de seguridad, ubicadas dentro o en las cercanías de clínicas psiquiátricas, estaban camufladas como salas de ducha, había cuartos de disección y crematorios especialmente instalados, en los cuales los cadáveres de los asesinados podían ser incinerados de inmediato ${ }^{1,6}$ (Fig. 1).

\section{Experimentos con sulfonamidas}

La eficacia terapéutica de las sulfonamidas para el tratamiento de lesiones similares a las de origen bélico fue investigada por el Dr. Karl Gebhardt, el cual no se limitó a realizar experimentos con sulfonamidas, sino que también participó en otros experimentos con prisioneros de campos de concentración (KZ, Konzentrationlager), por ejemplo en ensayos de trasplante óseo con prisioneros. En la serie de experimentos de sulfonamidas, a los prisioneros se les provocaban heridas intencionales, las cuales eran infectadas con estreptococos, Clostridium perfringens y tétanos. La circulación sanguínea era interrumpida ligando los vasos sanguíneos a ambos lados de la herida para lograr una situación semejante a una herida sufrida en el campo de batalla, se evolucionaba la herida a la complicación, infectándola, introduciendo 
astillas de madera y vidrio en polvo y tras infectar artificialmente, se comenzaba el tratamiento con sulfonamidas para poder evaluar con exactitud su eficacia. En estos experimentos no se empleaban anestésicos y en las observaciones se subdividían los prisioneros en tres grupos femeninos y tres masculinos. Así mismo, los alemanes realizaron experimentos con un preparado de sulfonamida, de nómina B 1034, administrado a un gran número de enfermos; este medicamento demostró ser eficaz, pero no dio resultado en el tratamiento de flegmones y varios casos de septicemia resultaron mortales ${ }^{1,7,8}$.

\section{Experimentos de flegmones}

Semejante a los experimentos de sulfonamidas era la formación y el tratamiento de flegmones en prisioneros, se les provocaba artificialmente para comprobar en ellos la eficacia de diversos medicamentos. Treinta prisioneros recibieron inyecciones de 2 a $3 \mathrm{~cm}^{3}$ de petróleo y después de ocho días aparecieron flemones purulentos; fueron incididos y las excreciones de las heridas se recolectaron en tubos de vidrio cerrados y esterilizados que se enviaban al Instituto de Breslau. En otro grupo de 10 hombres se realizaron otros experimentos que consistían en irritarles la piel mediante diversas sustancias químicas, a algunos se les trató con una solución de arcilla al $8 \%$ de ácido acético. Los tratamientos se realizaron durante una semana, diariamente: en hombros y piernas siempre en el mismo lugar. Pasada la semana se hicieron visibles graves irritaciones en la piel y en algunos casos llegaron a formarse úlceras, estas últimas curaban con dificultad y varias personas murieron por causa de estas infecciones experimentales. En estos experimentos se probó la eficacia de medicamentos alopáticos y homeopáticos ${ }^{2}$.

\section{Experimentos de tifus exantemático}

Se experimentaron con prisioneros de campos de concentración nuevos procedimientos de prevención y tratamiento de enfermedades infecciosas. Para poder probar con prontitud la eficacia de nuevas vacunas y medicamentos para terapia ofrecidos por la industria y a insistencia del Comisionado Mayor para Higiene de la SS, fue creada en el KZ de Buchenwald una sección para investigaciones de virus y tifus exantemático. Se realizaron: experimentos de vacunación con tifus exantemático en 20 personas, experimentos con medicamentos para terapia de tifus exantemático con 47 personas y pruebas de vacunas para tifus exantemático con 435 personas. Solo en ese año habían sido utilizadas 848 personas donde se probaron vacunas y medicamentos para terapia contra difteria, tifus y cólera. Como es prácticamente imposible cultivar las bacterias del tifus, se hacían cultivos de tifus en personas vivas ${ }^{4}$.

\section{Experimentos de esterilización}

Los experimentos de esterilización se realizaron en mujeres especialmente seleccionadas entre edades de 20 y 40 años que habían dado a luz y no habían dejado de menstruar en el campamento. Después de una entrevista médica detallada, las víctimas seleccionadas para el experimento eran obligadas a sentarse en una cama de exploración ginecológica. Se les inyectaba un medio de contraste radiológico en sus tubas uterinas y se les tomaba una placa radiográfica para evaluar la permeabilidad. Posteriormente a las víctimas se les ordenaba que corrieran por la habitación cierto tiempo y después se les realizaba otra radiografía; nuevamente se les inyectaba un líquido especial, probablemente una solución de formalina en sus trompas de Falopio. El experimento se repetía de tres a seis veces en las mismas mujeres a intervalos de tres a cuatro semanas. Se esperaba que la sustancia inyectada a todas las mujeres sometidas bloqueara las tubas uterinas después de seis semanas, lo que debía confirmarse en un examen de revisión realizado nuevamente con el uso de un agente de contraste. En la siguiente etapa del experimento, que fue planeado pero nunca realizado, después de un año las víctimas debían tener relaciones sexuales con prisioneros varones para probar la efectividad de este método de esterilización en la práctica. Las víctimas del experimento enfermaron, con inflamación de varias partes de los órganos reproductivos. Se desconoce su número exacto, pero se ha estimado en cientos. Las esterilizaciones también se realizaron mediante sesiones de rayos $X$ de 5 a 15 minutos en los órganos reproductores de las mujeres, un gran numero de las cuales murieron después de ser radiadas. Las que sobrevivieron fueron sometidas después de tres meses a dos operaciones de revisión, en las cuales sus ovarios fueron extirpados y examinados sucesivamente. A las víctimas masculinas se les radiaban los testículos y posteriormente eran castrados después de un mes. Las castraciones eran incompletas, extirpando al sujeto la cuarta parte o la mitad del testículo; en otras ocasiones, el testículo entero se mandaba a Breslau en un tubo esterilizado con formalina $10 \%$ para 
someterlo a un estudio histopatológico de los tejidos. Estos procedimientos quirúrgicos se realizaban con inyecciones intrarraquídeas de novocaína. Así mismo, los médicos alemanes obligaban a los pacientes castrados a masturbarse, les provocaban la erección mediante el masaje de sus glándulas prostáticas, cuando este trabajo cansaba utilizaban un instrumento de metal, que producía al paciente un gran dolor; el semen era examinado por un bacteriólogo, que determinaba la vitalidad de los espermatozoides, se podían observar las diferencias que había entre los espermatozoides vivos y los muertos. Las secuelas de estos experimentos fueron no solo infertilidad y castración, sino también complicaciones como quemaduras y abscesos, especialmente en la pared abdominal y los órganos reproductivos. Estos experimentos se realizaron a escala masiva. También hubo intentos de inseminar artificialmente a las mujeres en asociación con experimentos de esterilización ${ }^{9-11}$.

\section{Experimentos psicofisiológicos}

En una revista científica alemana se publicaron las observaciones desarrolladas sobre hemorragias provocadas a mujeres por una mala noticia, estos experimentos fueron hechos con mujeres cuya menstruación era normal, a las cuales se les informaba que serían fusiladas; esto les provocaba una hemorragia interna1,11. El Dr. Steinberg, de París, informa sobre sus experiencias en Auschwitz: cuatro prisioneros fueron los objetos de experimentación, cada uno debía beber un vaso con un líquido somnífero, cuya dosis mortal se quería determinar, dos bebieron un vomitivo mezclado con veneno. Los cuatro fueron llevados a un área donde un médico observaba los efectos del medicamento. Dos de ellos vomitaron y sobrevivieron luego de dormir profundamente durante once horas, los dos restantes murieron en la misma tarde. Ambos sobrevivientes, junto a otros dos nuevos, que habían reemplazado a los dos muertos del primer experimento, fueron utilizados al día siguiente para un nuevo experimento. Se les dio a beber una nueva mezcla; dos vomitaron y los otros dos murieron $^{12-14}$. En otro estudio realizado a prisioneras con insomnio, 20 internas aceptaron una dosis de cierto polvo blanco desconocido, probablemente a base de morfina, al día siguiente 10 de ellas habían muerto; el mismo experimento se verificó con mujeres de edad avanzada. La consecuencia fue que murieron 70 más en la misma noche ${ }^{11}$. Se realizaron experimentos para determinar la resistencia del organismo humano al hambre; en ellos los prisioneros, que sufrían de una combinación de emaciación y agotamiento, eran obligados a tomar grandes cantidades de sopa, tales experimentos resultaban la gran mayoría fatales ${ }^{11}$. Otro experimento sin sentido fue recostar a centenares de prisioneros enfermos bajo el sol abrasador. Los médicos alemanes querían averiguar cuánto tardaba en morir una persona enferma bajo el sol, sin agua ${ }^{11}$.

\section{Experimentos en el área de medicina de guerra}

El Dr. Sigmund Rascher es considerado como pionero de la investigación de baja presión atmosférica y congelamiento (temperaturas cercanas al punto de congelación). En las investigaciones de vuelos a gran altura, debía comprobarse la conducta del organismo humano a una altura de hasta $12,000 \mathrm{~m}$ y ante una repentina pérdida de presión atmosférica en aviones averiados. Cerca de 200 personas del KZ de Dachau fueron sometidas a los más duros esfuerzos físicos con repentinas caídas de presión y supresión del oxígeno, provocadas experimentalmente. De 70 a 80 prisioneros fallecieron durante o inmediatamente después de estos experimentos. Rascher solo describió reacciones y síntomas reconocibles externamente y realizó disecciones de los fallecidos ${ }^{1,11,15}$. Los efectos de temperaturas cercanas al punto de congelación debían comprobarse en una serie de experimentos, iniciada en Kiel por el Prof. Ernst Holzlöhner. A este equipo ingresó también Rascher como miembro investigador. En una serie de experimentos, se obligó a las personas a permanecer hasta tres horas en una tina con agua helada. En otras de las series se mantuvo a las personas durante varias horas desnudas y a la intemperie, con temperaturas muy por debajo del punto de congelación. Las víctimas gritaban de dolor al sufrir el congelamiento de partes del cuerpo. El probar métodos de recalentamiento constituía una parte integral de este programa de investigación. Estos iban desde baños calientes de cuerpo entero hasta la transmisión de calor animal por el cuerpo de animales o mujeres ${ }^{1,11,15}$. Otros experimentos de tipo térmicos se pueden destacar: a) en la lámpara de sol, los prisioneros se colocaban bajo lámparas de sol que estaban tan calientes que quemaban la piel, una víctima fue repetidamente congelada hasta la inconsciencia, entonces era reavivada con las lámparas hasta que estuviera sudando; b)en la irrigación interior al prisionero se le introducía vigorosamente en el estómago, vejiga e intestinos, agua calentada a una temperatura abrasadora; c) en el baño caliente el prisionero era colocado en agua caliente y la temperatura se aumentaba despacio, este método demostraba ser el mejor ${ }^{16}$. 


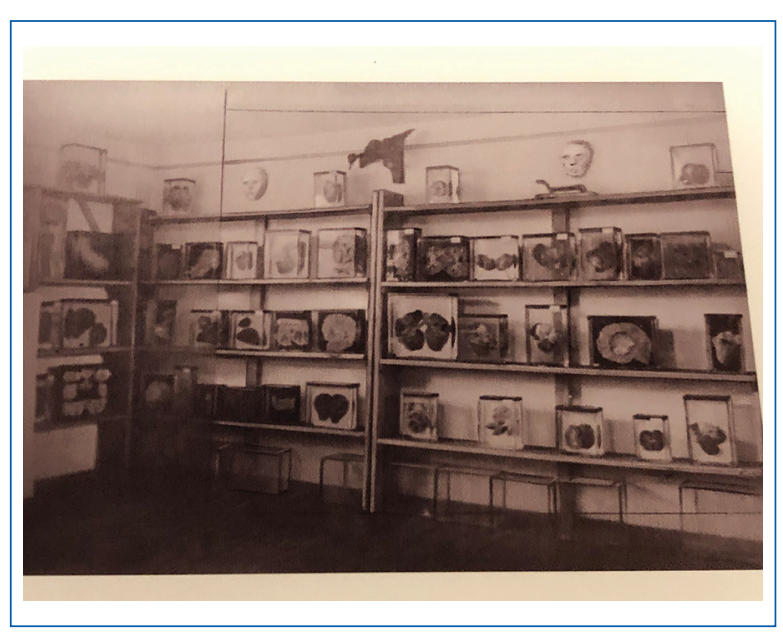

Figura 2. Acervo anatómico.

\section{Recolección de material anatómico}

El absoluto poder sobre la vida o la muerte de prisioneros en los $\mathrm{KZ}$ indujo a los médicos partícipes de la dominación nazi a considerar a los prisioneros como «material humano» disponible y a utilizarlo sin miramientos. Estos preparados eran valiosos porque provenían de gente absolutamente sana que, o había sido ahorcada o enviada a los hornos crematorios ${ }^{4,17}$ (Fig. 2).

\section{Cámaras de gas}

El gas del ciclón $B(Z y k l o n ~ B)$, que contiene cianuro de hidrógeno, se utilizó por primera vez en Auschwitz para el asesinato en masa de prisioneros el 3 de septiembre de 1941. La primera ejecución por gas fue un caos, ya que las víctimas estaban aún vestidas (a nadie se le ocurrió desvestirlos), los cadáveres eran un enredo de cuerpos, prendas, heces, orina y sangre menstrual. La ejecución consistía en introducir a grandes grupos de personas desnudas en la cámara, la cual en los techos tenía regaderas por las cuales salía el gas una vez encendido un motor diésel; la mayor parte de las víctimas moría a los 25 minutos de haberse puesto en funcionamiento el motor. Las víctimas se lanzaban en estampida hacia las salidas, que eran sólidas puertas de metal. Así pisoteaban a niños, mujeres, ancianos y personas débiles. Algunos trataban de ascender por encima del gas, trepando sobre los cuerpos de los caídos. La agonía duraba cuatro o cinco minutos. Los cadáveres estaban empapados de sudor y orina, con las piernas manchadas de excremento y sangre menstrual. La inhalación de gas cianuro destruye el

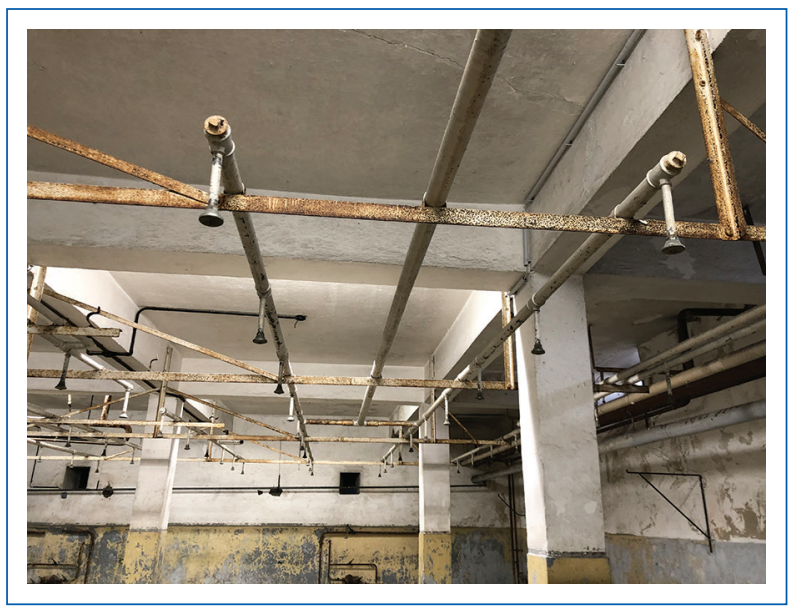

Figura 3. Regaderas.

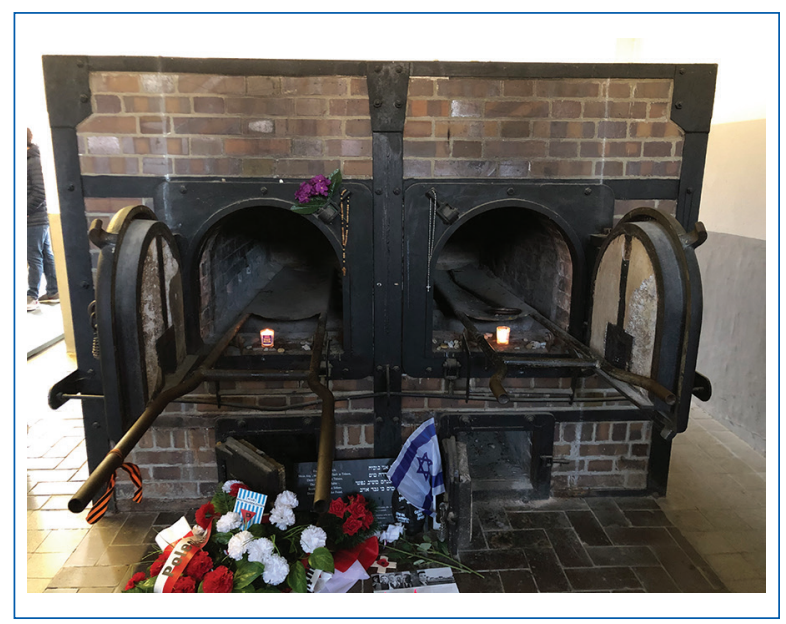

Figura 4. Hornos crematorios.

mecanismo por el cual las células rojas de la sangre retienen el oxígeno. Los síntomas son: pérdida de control intestinal, hemorragias y, finalmente, parálisis del sistema respiratorio, que lleva a la asfixia. Finalmente los cuerpos eran llevados a los hornos para su cremación ${ }^{18,19}$ (Figs. 3-5).

\section{Campos de concentración como centros de investigación}

\section{Auschwitz}

Dentro de las investigaciones realizadas en este KZ se pueden destacar los métodos de esterilización descritos anteriormente y los experimentos con enfermedades 


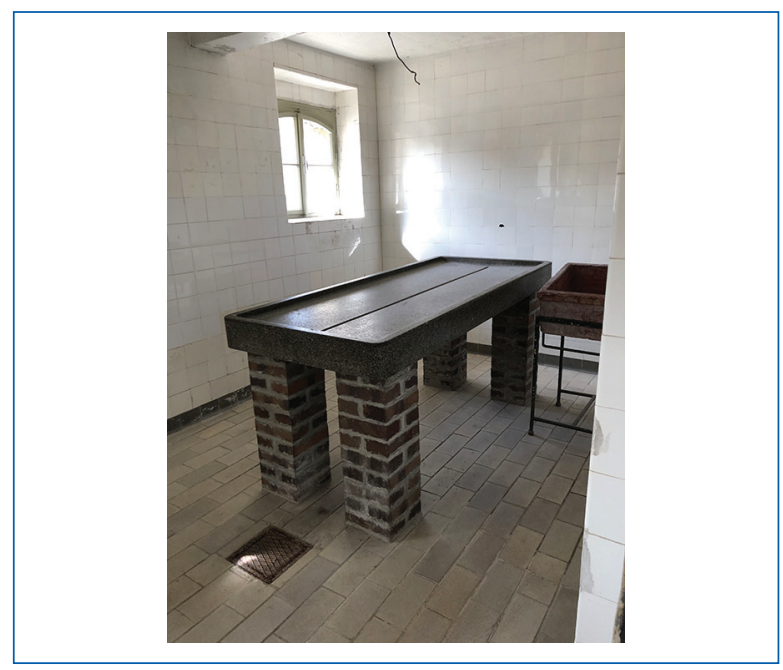

Figura 5. Mesa de disección.

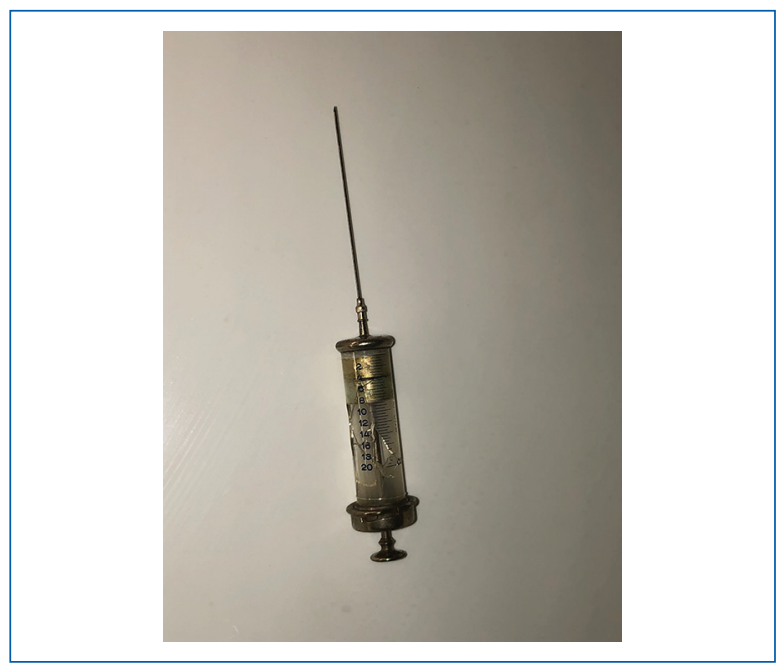

Figura 6. Jeringa para múltiples usos en investigación.

infecciosas como tifus, tuberculosis y malaria. Durchfall era un término general para las enfermedades infecciosas más peligrosas, como disentería, escarlatina, difteria, fiebre tifoidea, tuberculosis o erisipela. Los documentas relacionados con las investigaciones farmacológicos muestran ensayos con eleudron (una sulfamida de acción corta, que solía ser un antimicrobiano oral y tópico común hasta que se descubrieron alternativas menos tóxicas) y sulfapiridina (un medicamento antibacteriano sulfanilamida que en un tiempo se conoció como M\&B 693, la sulfapiridina ya no se prescribe para el tratamiento de infecciones en humanos ${ }^{20}$, también hubo experimentos a gran escala con el uso de sustancias llamadas Be-1032, Be-1034, 3582, rutenol (el nombre de un medicamento descontinuado), y periston ${ }^{21}$ (polímero de polivinilo de peso molecular variable que se emplea como agente de suspensión y dispersión y vehículo para productos farmacéuticos, también se utiliza como expansor del volumen sanguíneo). Estos medicamentos fueron probados para una variedad de enfermedades infecciosas en sujetos infectados para el experimento, principalmente tifus y tuberculosis, y en los flegmones. Otro tipo de experimento involucraba la aplicación de narcóticos, cuyo propósito era hacer que los sujetos revelaran información. Otros ensayos incluyeron la administración de acrichina (un tintura antiinfecciosa altamente fluorescente utilizada clínicamente como antiséptico tópico y experimentalmente como mutágeno, debido a su interacción con el ADN) ${ }^{22}$ para inducir ictericia, fabricación de moldes de yeso de los órganos sexuales de las mujeres y la aplicación de descargas eléctricas. Se realizaron proyectos de investigación sobre el cáncer que implicaron la extracción de grandes partes del cuello uterino de las reclusas, a las mujeres se les implantó tejido canceroso en el útero con fines experimentales. Las SS emplearon una serie de procedimientos para matar a pacientes gravemente enfermos en el hospital del campo de Auschwitz, los cuales consistieron en inyecciones intravenosas de peróxido de hidrógeno, gasolina, evipán y fenol. El fenol también se usó para matar a pacientes que recibían tratamiento en el hospital, incluso a los convalecientes, seleccionados presuntamente para controlar brotes, especialmente tifus ${ }^{10,11,18,23-27}$ (Fig. 6).

\section{Ravensbrück}

Se realizaron los siguientes tipos de experimentos biológicos: procedimientos quirúrgicos realizados para examinar los efectos de las infecciones quirúrgicas por microorganismos formadores de pus y/o gangrena gaseosa, generalmente estafilococos, estreptococos, Clostridium perfringens y Clostridium novyi inyectados en los músculos de la pierna o insertados en una herida abierta. Los experimentos se realizaron para probar las propiedades terapéuticas de las sulfonamidas y otros medicamentos, que se colocaron en la herida infectada. Se realizaron cirugías asépticas óseas, musculares y neuronales, cuyo objetivo era observar la regeneración celular. Se practicaron tres tipos de procedimiento quirúrgico a nivel óseo: fracturas (los huesos de la parte inferior de la pierna se expusieron quirúrgicamente, se rompieron y se unieron con abrazaderas, se cosió la herida y la pierna se puso en yeso); trasplantes de hueso (la tibia izquierda se trasplantó a la tibia derecha y viceversa, o el peroné se trasplantó a la tibia), y un 
procedimiento llamado Knochenspäne, que involucra una incisión para obtener una astilla ósea, que luego se retiraría en una segunda operación, junto con un pedazo del hueso en el que se encontraba. Las cirugías neuronales implicaron la extracción de algunos de los nervios en la parte inferior de la pierna. Se conocen casos de epilépticos a los que se les extirparon las glándulas suprarrenales, y estas glándulas se trasplantaron posteriormente a asmáticos bronquiales. Las mujeres fueron esterilizadas al extirparles la parte media o la totalidad de los ovarios. Otros tipos de experimentos incluyeron experimentos de malaria y enemas realizados en pacientes con tifus con el uso de orina de mujeres embarazadas $8,10,27-30$.

\section{Dachau}

El tipo predominante de investigaciones en este $\mathrm{KZ}$ fueron los experimentos de la Luftwaffe, de baja presión, bajas temperaturas y las observaciones de los efectos del agua de mar en el cuerpo humano comentados anteriormente. Se realizó un conjunto de experimentos para probar la practicidad del agua de mar para beber. Los experimentos de malaria eran para encontrar una sustancia que hiciera al cuerpo humano resistente a los parásitos de dicha enfermedad. Otro tipo de experimento llevado a cabo era el estudio de manejo de flegmones, antes comentado. Se utilizaron métodos experimentales para tratar a los presos que padecían tuberculosis; estos recibieron tratamiento con calcio, codeína, les generaron neumotórax y se les practicó diversos procedimientos quirúrgicos, algunos de ellos se mantuvieron en la cama sin medicamentos ni alimentos adicionales, otros recibieron tratamiento homeopático, a los pacientes con tuberculosis se les obligó a hacer ejercicio, caminatas y baños con agua fría. Se realizaron pruebas de hematología con una sustancia llamada polygal-10 que se suponía que aumentaría la coagulación sanguínea. A algunas víctimas se les amputaron las extremidades y se les trasplantaron vasos sanguíneos a otras personas ${ }^{10,31}$.

\section{Buchenwald}

Los experimentos que se realizaron fueron principalmente con el tifus, pero también se realizaron ensayos para examinar la tolerancia del cuerpo humano a una variedad de vacunas contra la malaria y a una vacuna compuesta contra la viruela, fiebre tifoidea, tifus, paratifoidea A y B, cólera y difteria. Se llevaron a cabo experimentos para evaluar la efectividad de una

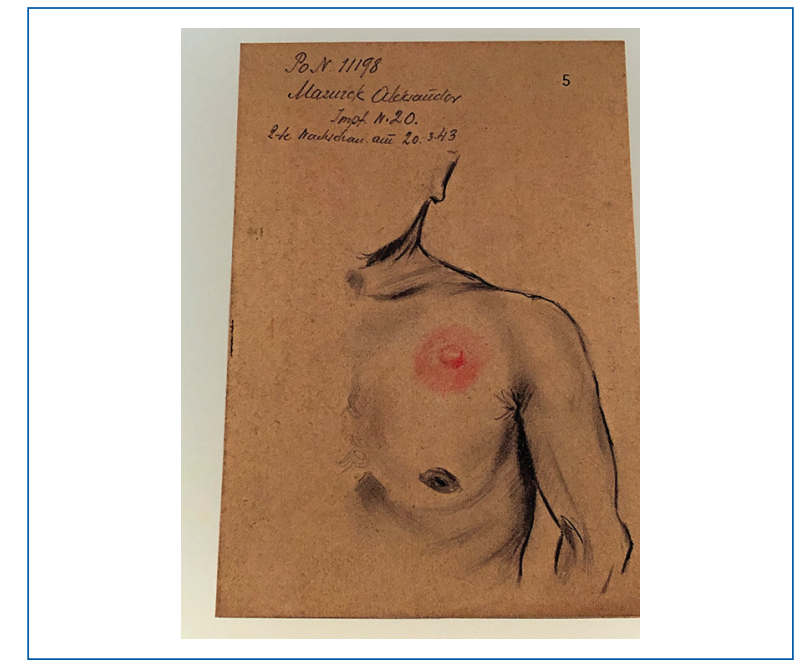

Figura 7. Ilustración de reacción cutánea relacionada por experimentos con vacunas.

variedad de medicamentos farmacéuticos en el tratamiento de quemaduras por fósforo y caucho. Se emplearon bombas incendiarias para inducir quemaduras en las víctimas de estos experimentos. Se probaron diversos venenos en el cuerpo humano, por ejemplo, los derivados alcaloides se pusieron en la sopa de las víctimas, o se dispararon balas recubiertas con nitrato de aconitina en los muslos de las víctimas. Otros experimentos involucraron inyecciones intravenosas de varias dosis de suero sanguíneo caduco, el objetivo era determinar la utilidad terapéutica del plasma humano almacenado en condiciones de campo más allá de su fecha de caducidad. Otros experimentos incluyeron el tratamiento de heridas infectadas con ácido carbólico concentrado y el «tratamiento" de la homosexualidad con inyecciones de grandes dosis de hormonas masculinas ${ }^{10,11,27,32}$.

\section{Sachsenhausen, Oranienburg}

Se realizaron procedimientos quirúrgicos tales como la creación de una segunda vejiga, hecha de un asa intestinal separada. Varios niños fueron infectados con hepatitis viral, el objetivo de este experimento fue identificar la causa de la enfermedad y desarrollar una vacuna apropiada (Fig. 7). Otros experimentos involucraron intentos de tratar la tuberculosis mediante la administración de inhalaciones de diversas sustancias y los cálculos renales mediante un método de dilución. Un grupo de víctimas sufrió graves infecciones locales y diseminadas causadas por cortes profundos en los 
músculos superiores de la pierna, en los que se introdujeron materiales infectados. Se hicieron observaciones sobre el desarrollo y las etapas de la infección, así como los efectos de una variedad de sustancias terapéuticas. Otro grupo de víctimas tuvo quemaduras inducidas artificialmente causadas por armas químicas, principalmente gas mostaza, aplicadas a diferentes partes del cuerpo; las quemaduras resultantes fueron tratadas con una variedad de sustancias. Había una compañía que estaba involucrada en probar la durabilidad del calzado y los efectos de las drogas estimulantes ${ }^{10,32}$.

\section{Natzweiler}

Se realizaron experimentos sobre la eficacia de varias vacunas contra el tifus, se llevaron a cabo experimentos para encontrar el método más efectivo para el tratamiento de las quemaduras de gas mostaza. Se hicieron intentos para tratar el envenenamiento por fosgeno con hexametilenotetramina ${ }^{10,33-35}$.

\section{Neuengamme}

A un grupo formado por hombres de 20 a 30 años con un estado avanzado de tuberculosis pulmonar unilateral o bilateral, tuberculosis extrapulmonar e individuos sanos se les aplicó una dosis de bacilos de tuberculosis mediante inyección subcutánea o intradérmica en la región de la axila; además, las víctimas tenían la piel del pecho escarificada y los bacilos se frotaban en los cortes. El proceso se controló mediante rayos $\mathrm{X}$ y dio como resultado tuberculosis pulmonar secundaria abierta. Se llevaron a cabo experimentos análogos en niños ${ }^{10,36}$.

\section{Gross-Rosen}

Se hicieron intentos en este campo para tratar la fiebre tifoidea con métodos experimentales especiales, se utilizó un líquido corrosivo en un recinto cerrado para prisioneros. Se tomaron muestras de su ropa y del equipo para las pruebas. El objetivo era encontrar el mejor método de desinfección y control de insectos ${ }^{10,37-39}$.

\section{Mauthausen y Gusen, Stutthof, Flossenbürg, Majdanek, München}

En estos campamentos se llevaron a cabo una variedad de procedimientos quirúrgicos, con el objetivo de mejorar la práctica médica. Se incluyeron operaciones en estómago, hígado, riñones y cerebro. Experimentos con enfermedades infecciosas, condiciones ginecológicas y toxicología. Se realizaron pruebas en prisioneros para examinar la nocividad de una variedad de alimentos. Uno de los proyectos de investigación realizados era examinar los efectos en el cuerpo humano al pasar una corriente eléctrica a través del cráne $0^{10,23}$.

\section{Conclusión}

Todo el personal de salud desde su formación debe conocer este tipo de temas, que aunque son tristes no deben pasarse por alto 0 darse por vistos, ya que ello concienciará a los estudiantes de la importancia de estos experimentos, que en muchas ocasiones se siguen empleando en algunos laboratorios clandestinos del mundo con hombres, mujeres y niños de todas las razas, condiciones sociales e ideología políticas y religiosas igual que en la Segunda Guerra Mundial.

\section{Contribuciones de los autores}

Las fotos de los campos de concentración de Mauthausen fueron proporcionadas directamente por los autores para la elaboración del artículo.

\section{Financiamiento}

La presente investigación no ha recibido ayudas específicas provenientes de agencias del sector público, sector comercial o entidades sin ánimo de lucro.

\section{Conflicto de intereses}

Los autores declaran no tener conflicto de intereses alguno.

\section{Responsabilidades éticas}

Protección de personas y animales. Los autores declaran que para esta investigación no se han realizado experimentos en seres humanos ni en animales.

Confidencialidad de los datos. Los autores declaran que en este artículo no aparecen datos de pacientes.

Derecho a la privacidad y consentimiento informado. Los autores declaran que en este artículo no aparecen datos de pacientes. 


\section{Bibliografía}

1. Riquelme H. La medicina bajo el nazismo: una aproximación histórico-cultural. Medicina UPB. 2004;23(1):25-47.

2. Riquelme H. La medicina nacionalsocialista: ruptura de cánones éticos en una perspectiva históricocultural. Polis. 2005:10:1-30.

3. Ortega L. Vida y obra de Josef Mengele «El ángel de la muerte» (1911 1979). Evid Med Invest Salud. 2013;6(2):71-2.

4. Riquelme H. La medicina en el Nacional Socialismo: gestiones de oposición profesional. Polis. 2006;13:1-14

5. Hernández H, Pérez A, Padilla D, Negrín A. Acercamiento a la medicina mortal del nazismo. 2017;56(263):36-40.

6. García J. La medicina sin rostro humano: eutanasia y experimentos médicos durante el Tercer Reich. Medicina e Historia. 2005;1:4-9.

7. Roelcke V. Sulfonamide-research on human subjects in Nazi concentration camps: a critical re-evaluation of the epistemological and ethical dimensión. Medizinhist J. 2009;44(1):42-60.

8. Bagatur E. Nazi Medicine Part 1: Musculoskeletal experimentation on concentration camp prisoners during World War II. Clin Orth Rel Res. 2018;476(10):1899-905.

9. Fejkiel W. On the so-called negative demography, or Prof. Clauberg's experiments. Polski Tygodnik Lekarski. 1957;8:305-8.

10. Jakubik A, Jan Ryn Z. Pseudo-medical experiments in Hitler's concentration camps [Internet]. Medical Review Auschwitz [fecha de consulta: 22/05/20]. Disponible en: https://www.mp.pl/auschwitz/journal/ english/170062, pseudo-medical-experiments-in-hitlers-concentration-camps

11. Lengyel O. Los hornos de Hitler. 1.a ed. México: Diana; 1961.

12. Vine NC. Psychology under the Third Reich [Internet]. Worcester Polytechnic Institute; 2009 [fecha de consulta: 22/05/20]. Disponible en: https:// digitalcommons.wpi.edu/iqp-all/2080/

13. Strous RD. Psychiatry during the Nazi era: ethical lessons for the modern professional. Annals of General Psychiatry 2007. Ann Gen Psychiatry. 2007;6:8.

14. Seeman M. Psychiatry in the Nazi Era. Can J Psych. 2005;50:218-25

15. Bogod D. The Nazi hypothermia experiments: forbidden data? Anaesthesia. 2004;59(12):1155-6.

16. Zúñiga I, Aguiar N, Zaragoza C, Herbas I, Caro J. Lo que la historia de la medicina no puede olvidar: experimentos nazis. $1 .^{\text {era }}$ parte. Boletín de Epidemiología. 2007;24(36):1-3.

17. Czecha H, Brenner E. Nazi victims on the dissection table. The Anatomical Institute in Innsbruck. Ann Anat. 2019:226:84-95

18. Kłodziński S. Phenol in Auschwitz-Birkenau [Internet]. Medical Review Auschwitz [fecha de consulta: 22/05/20]. Disponible en: https://www.mp.pl/auschwitz/journal/english/222711, phenol-in-auschwitz-birkenau
19. Retamal F. El médico-demonio del Tercer Reich, Josef Mengele: "el ángel de la muerte" ha caído en Auschwitz. Tesis para optar al Título de Profesor de Educación Media en Historia y Geografía. Chile: Universidad del Bío-Bío, Facultad de Educación y Humanidades, Departamento de Ciencias Sociales, Escuela de Pedagogía en Historia y Geografía; 2013.

20. Sulfapyridine [Internet]. Drugs.com [fecha de consulta: 22/05/20]. Disponible en: https://www.drugs.com/international/sulfapyridine.html

21. Periston [Internet]. Le Parisien. Sensagent [fecha de consulta: 22/05/20]. Disponible en: http://dictionnaire.sensagent.leparisien.fr/Periston/en-en/

22. Aminoacridine [Internet]. Le Parisien. Sensagent [fecha de consulta: 22/05/20]. Disponible en: http://dictionnaire.sensagent.leparisien.fr/Aminoacridine/en-en/

23. Dąbrowska G, Dąbrowski G. Human cruelty and German cruelty. Warszawa: Wydawnictwo Wiedza; 1946: 71

24. Kowalczykowa J. Starvation sickness in Auschwitz. Przeglad Lekarski. 1948;1a:58-61.

25. Fejkiel W. Induced typhus infections in the concentration camps. Przeglad Lekarski. 1955:4:97-103.

26. Kłodziński S. Criminal pharmacological experiments on Auschwitz prisoners (substance 3582, rutenol, Be-1034, periston). Przegląd Lekarski. 1965;1:40-6.

27. Zúñiga I, Aguiar N, Zaragoza C, Herbas I, Caro J. Lo que la historia de la medicina no puede olvidar: experimentos nazis. $2{ }^{a}$ parte. Boletín de Epidemiología. 2007;24(37):1-3

28. Klimek H. Beyond human capacity. Recollections of women operated on at Ravensbrück. Warszawa: Książka i Wiedza; 1968.

29. Półtawska W. And l'm scared of nightmares. Warszawa: Czytelnik; 1962

30. Półtawska W. Experimental operations at Ravensbrück concentration camp. Przeglad Lekarski. 1963;1a:90-7.

31. Musioł T. Dachau 1933-1945. Materials on experiments conducted on human subjects at Dachau. Archives of the Chief Commission for the Investigation of Nazi Crimes in Poland 1968, estante n. ${ }^{\circ} 22$ ob.

32. Mikulski J. The activities of the Typhus and Virus Research Department of the Waffen SS Institute of Hygiene. Biuletyn Głównej Komisji Badania Zbrodni Hitlerowskich w Polsce. 1971;23:151-96.

33. Zegarski W. The hospital at Sachsenhausen in the context of conditions in the camp, 1940-1945.Przeglad Lekarski. 1965;1:75-86.

34. Natzweiler - Trial of 50 members of the camp's staff. Archives of the Chief Commission for the Investigation of Nazi Crimes in Poland, estante n. ${ }^{\circ} 45 \mathrm{ob}$.

35. Mitscherlich A, Mielke F. Medizin ohne Menschlichkeit: Dokumente des Nürnberger Ärzteprozesses. Fráncfort del Meno: Fischer Bücherei; 1949. Traducido al inglés como The Death Doctors. Londres: Elek Books; 1962.

36. Kłodziński S. Criminal tuberculosis experiments conducted in Nazi concentration camps in World War 2. Przegląd Lekarski. 1962;1a:77-81.

37. Konopka S. The camp hospital at Gross-Rosen (A passage from my memoirs). Polski Tygodnik Lekarski. 1946;2:64-8.

38. Gładysz A. The death camp Łódź. Wydawnictwo Łódzkie; 1962.

39. Mołdawa M. Gross-Rosen. A concentration camp in Silesia. Warszawa: Wydawnictwo Polonia; 1967 